\title{
Characteristics of Patients, Self-Efficacy and Quality of Life among Patients with Type 2 Diabetes Mellitus
}

\author{
Karina Megasari Winahyu ${ }^{1}$, Revi Anggita ${ }^{2}$, Giri Widakdo ${ }^{3}$ \\ ${ }^{1,2}$ Faculty of Health Science, Universitas Muhammadiyah Tangerang, Tangerang, Banten, Indonesia \\ ${ }^{3}$ Faculty of Nursing, Universitas Muhammadiyah Jakarta, Jakarta, Indonesia \\ Corresponding email: karinawinahyu@yahoo.com
}

Submitted: 04-04-2019 Accepted: 12-12-2019 Published: 12-12-2019

\begin{abstract}
Diabetes mellitus as a chronic disease requires a long-term care, which influence the quality of life (QOL). A mechanism perceived by the patients who engage in long-term treatment, such as self-efficacy (SE) is prerequisite for the success of disease management. The study aimed to identify the relationship between characteristics of patients, SE and domains of QOL among patients with type 2 diabetes mellitus (T2DM) living in community. The study used a correlational analytical with a cross-sectional approach and recruited 105 patients with type 2 diabetes in Sukasari Public Health Center, Tangerang. Self-administered questionnaires were used to measure sociodemographic of T2DM patients, while the Diabetes Management Self-Efficacy Scale (DMSES) UK and Asian Diabetes Quality of Life (Asian DQOL) were used to measure SF and QOL, respectively. Data were analyzed using Spearman Rank-Order Correlation. The study revealed that characteristics of patients, including age and period of illness were negatively associated with memory and cognition domains of QOL, while years of education positively associated interpersonal relationship domains of QOL. For SE, it was positively significant associated with diet habit, energy, and financial aspects domains of QOL. The SE was positively associated with the QOL $(r=0.31$; $\mathrm{p}$-value $\leq 0.01)$. The SE is relationship with QOL of T2DM. Therefore, health care provider should need to maintain the domains of QOL through improving SE, while considering the characteristics of T2DM patients, including age, period of illness, and years of education.
\end{abstract}

Keywords: Characteristics of patients, self-efficacy, type 2 diabetes mellitus, quality of life domains. 
Karina Megasari Winahyu: Characteristics of Patients, Self-Efficacy and Quality of Life among Patients

\section{Introduction}

Diabetes mellitus is a global concern since its chronicity impairing and devastating for the life of the people living with the disease. It is no longer affected developed country but also developing country. Report of International Diabetes Federation (IDF) in 2017 revealed that there are 425 million of people with diabetes and predicted to reach up to $48 \%$ in 2045 in the world. Moreover, South East Asia was the top prevalence since there are 82 million of people with diabetes compared to other region around the world (International Diabetes Federation, 2017). Indonesia as a low middle income county contributed to 7.6 million of people with diabetes mellitus (DM) and made to be the fourth largest country related to number of undiagnosed diabetes for aged 20-79 years old in 2017 (International Diabetes Federation, 2017). The rising prevalence of the disease showed that many people with diabetes who will experience the long term treatment, which could affect their quality of life. Moreover.

Quality of life among patients with diabetes mellitus is an important issue since chronic disease could impair some domains of patient's life. Quality of life is a concept that relates to the well-being of patients in terms of physical, psychological, social and environmental (World Health Organization, 2019). The length of time suffering from diabetes mellitus and the treatment that is undertaken can affect the functional, psychological, and health capacity and quality of life of patients (Wahyuni, Nursiswanti, \& Anna, 2017). Most of patients with Type 2 Diabetes Mellitus reported poor quality of life (Yamin \& Sari, 2018). Quality of life of patients with diabetes mellitus is one of the main focuses in treatment. Quality of life is very important to get serious attention since it closely related to morbidity, such as patients with emotional distress are more likely to decrease their QoL (Gomez-Pimienta et al., 2019). In addition, the ability to manage diabetes will affect the QoL (Afzan et al., 2018).

Self-management in diabetes is necessary for the patient to engage in the long termcare, and one strong predictor of diabetes management is self-efficacy (Kim, Song, \&
Kim, 2019). Moreover, good management of diabetes lead to better health outcome. It was consistent with previous study found that self-efficacy was one of several factors affecting the quality of life among patients with diabetes mellitus (Rahman \& Sukmarini, 2017).

Self-efficacy is an individual's belief in the ability to self-regulate and carry out the tasks needed to achieve the expected results. Selfefficacy determines individuals to feel, think, motivate themselves and behave to achieve the desired goals (Bandura, n.d.). Self-efficacy in patients with diabetes mellitus focuses on their beliefs about their ability to perform diabetes self-care behaviors (Al-Khawaldeh, Al-Hassan, \& Froelicher, 2012). Self-efficacy encourages self-control processes to maintain the behaviors needed to manage self-care in patients (Gedengurah, 2011). Self-efficacy in type 2 diabetes mellitus patients focuses on patient confidence to be able to perform behaviors that can support the improvement of their disease and improve self-care management such as diet, physical exercise, medication, glucose control and treatment of diabetes mellitus in general (Gedengurah, 2011).

Most of study on self-efficacy and the quality of life among patients with type $2 \mathrm{DM}$ obtained from various standard instruments, which constructed from western culture. The existence of differences in measuring instruments and the limited studies in Indonesia using instruments that have been found to be most effective and in accordance with culture of Indonesia. Therefore, this study want to identify the association between characteristics of patients, self-efficacy and domains of quality of life among patients with type 2 diabetes mellitus in Indonesia.

\section{Method}

This study was a correlation analysis with a cross-sectional approach. This study was conducted at Sukasari primary health center (puskesmas) in Tangerang City from April to June 2018. Participants in this study were 105 patients with type 2 diabetes mellitus. The Participants were selected by consecutive sampling technique. The inclusion criteria 
Karina Megasari Winahyu: Characteristics of Patients, Self-Efficacy and Quality of Life among Patients

participants in this study were type 2 diabetics who have had diabetes for at least one year, can communicate verbally, able to provide informed consent. Meanwhile, patient with dementia or Alzheimer's disease were excluded in this study.

The characteristics of patients comprises of gender, marital status, level of education and period of illness were measured by selfreported questionnaire developed by the researcher. Moreover, the instrument used to measure the quality of life in this study is the Asian Diabetes Quality of Life (Asian DQoL). The Asian DQoL instrument is a tool developed by Goh in 2014 and has been tested on the Malaysian and Singaporean population which is considered a representation of ethnic Malays, Chinese and English living in Asia (Goh, Rusli, \& Khalid, 2015). It consists of 21 items, including financial, diet, memory and cognition, energy and relationship component. This 5 Likert scale measured quality of life which higher score indicates higher quality of life. The researchers have been allowed to use the Asian DQoL instrument in this study. This instrument has been tested for validity and reliability with a Cronbach alpha value of 0.91 .

The instrument used to measure selfefficacy in this study was the Diabetes Mellitus Self Efficacy Scale of the United Kingdom (DMSES UK). DMSES UK is an instrument developed by Sturt in 2009. This questionnaire consists of 15 items with 0 to 10-point scale, which higher score indicating high self-efficacy. The DMSES UK can be used to measure self-efficacy for self-care for type 2 diabetes both in clinical areas and in the study area (Sturt, Hearnshaw, \& Wakelin,
2010). This instrument has been tested for validity and reliability with a Cronbach alpha value of 0.95 .

Prior to data collection, this study had been granted ethical approval from Health Research Ethics Committee with letter number 445/089-KEP-RSUTNG. The data collection was done by interviewing prospective participants to identify participants for this study. The researcher explained the procedure and asked for willingness of the recruited participants to fill out informed consent.

The data in this study were not normally distributed. Therefore, the association between characteristics of patients, including age, years of education, period of illness, self-efficacy and all domains of quality of life were measured by Spearman Rank-Order Correlation analysis $(\mathrm{p}<.05)$.

\section{Results}

\section{Characteristics of patients}

Out of 105 patients with type 2 diabetes mellitus, $70.5 \%$ were female, the marital statuses were married ( $80 \%)$, and levels of education were senior secondary school (42 $\%$ ). Out of the total respondents, period of illness ranged from 1 year until 20 years $(\mathrm{M}$ $=6.18$ years, $\mathrm{SD}=4.67$ years $)$ and $71.5 \%$ were age of 56-65 years old.

Association between characteristics of patients, self-efficacy and quality of life.

Results of the Spearman correlation indicated that there were no significantly association between characteristics of patients and quality of life (Table 1). However, there was significant association between

Table 1 Association between Characteristics of Patients, Self-Efficacy and Quality of Life among Patients with Type 2 Diabetes Mellitus $(\mathrm{N}=105)$

\begin{tabular}{lcccc}
\hline \multicolumn{1}{c}{ Variables } & Age & Years of Education & Period of Illness & Self-Efficacy \\
\hline Quality of Life & -0.04 & 0.06 & -0.12 & $0.31^{* *}$ \\
- Diet habit & 0.10 & 0.15 & -0.16 & $0.47^{* *}$ \\
- Energy & -0.06 & 0.02 & -0.09 & $0.40^{* *}$ \\
- Memory and & -0.21 & -0.12 & $-0.35^{* *}$ & 0.08 \\
cognition & & & & \\
- Financial Aspects & 0.08 & 0.04 & -0.11 & $0.32^{* *}$ \\
- Interpersonal & 0.00 & $0.23^{*}$ & -0.01 & 0.13 \\
relationship & & & & \\
\hline
\end{tabular}

Note: ${ }^{*} p<.05 ; * * p<.001$ 
Karina Megasari Winahyu: Characteristics of Patients, Self-Efficacy and Quality of Life among Patients

characteristics of patients and quality of life domains. A positive correlation was found between years of education and interpersonal relationship domain $(\mathrm{r}=.23 ; \mathrm{p}=.032) ; \mathrm{a}$ negative correlation between period of illness and memory $\&$ cognition domain $(r=-.35, \mathrm{p}$ $=.000)$; a positive correlation between age and memory and cognition $(r=.21 ; \mathrm{p}=.032)$. It is showed that self-efficacy was positively correlated with quality of life. Moreover, self-efficacy was associated with diet habit, energy, and financial aspects domains.

\section{Discussion}

The results of this study found that there were relationships between characteristics of patients, self-efficacy and QoL among patients with type 2 diabetes mellitus. It was consistent with results from previous studies (Amelia, Ariga, Rusdiana, Sari, \& Savira, 2018; Wang, Chen, Yang, \& Juan, 2017), which will be explained further as follows.

The result of this study showed that characteristics of patients with DM had association with some domains of QoL. Concerning the association between age and memory and cognition indicated that T2DM patients who are older more like to perceive lower score on memory and cognition. As people become older, their memory and cognition function could deteriorate (Bahk \& Choi, 2018). It was supported that $75 \%$ of the age of respondents are ranged 56-65 years old. Moreover, the complexity of the diabetes management could be related to how these patients perceive their satisfaction in terms of ability to recall or recognize events or things.

Concerning the relationship between period of illness and memory \& cognition, it showed that patients with DM who had longer period of illness more likely to show a decline of recalling ability. A study of Hazari et al. indicated that patients with disease duration over 5 years were more prominent to experienced cognitive deterioration (Hazari, Ram Reddy, Uzma, \& Santhosh Kumar, 2015). However, there were no significant relationship between the duration of illness and cognitive function in previous study. The inconsistency might because of the cognitive function in the present study was measured by decision making and memory recall power, while the previous study measured the cognitive function by P300 that use a speed of neural events linked to short memory.

Regarding the self-efficacy, the results showed that self-efficacy was associated with some domains of QoL, including dietary habit, energy, memory and cognition, and financial aspects. Perceived self-efficacy is the beliefs about own competencies to accomplish any task, which influence to the life through four psychological processes, such as cognitive, motivation, affective and selection process (Bandura, n.d.). Selfefficacy perceived by the patients could be an important factor that make people achieve difficult task as a challenge and immerse in their activities. For instance, patients with diabetes who perceived high self-efficacy will be more motivated to engage to the diet for DM since the patients feel confidence to be able to complete the dietary requirement.

The change as the impact of the diabetes perceived by the patients as a challenge need to be managed appropriately. Furthermore, the patients will be more likely to fulfil their regimen eagerly. According to Bandura, selfefficacy affects people to reduce stress since any threatening conditions recognized as an experience that they can control over them (Bandura, n.d.). The finding of this study was in line with a previous study stated that perceived self-efficacy associated with quality of life domains (Amelia et al., 2018; Bowen et al., 2015; Kurnia \& Kusumaningrum, 2017; Walker, Smalls, Hernandez-Tejada, Campbell, \& Egede, 2014). People who perceived higher self-efficacy tend to be able apply diabetes management, including diet, regiment, and exercise requirement. Consequently, the patients who have high self-efficacy will eventually have a good management of the disease, leading to perceive higher satisfaction in their aspects of life.

\section{Conclusion}

The findings revealed that the characteristics of patients and self-efficacy were significantly associated with quality of life domains. The 
Karina Megasari Winahyu: Characteristics of Patients, Self-Efficacy and Quality of Life among Patients

study suggests that the higher score of quality of life domains will be achieved by enhancing self-efficacy perceived by the patients with diabetes. Thus, this study can be a baseline data to develop self-efficacy intervention for improving the QoL by considering group of patients related to their age, years of education and period of illness.

\section{References}

Afzan, A., Al-Mahmood, S.M., Razak, T.B., Nur, N., Ahmad, F.N., Mohamed, A.H., Che, S.T., \& Abdullah. (2018). A cross-sectional study on the quality of life of patients with peripheral diabetic neuropathy pain in Hospital Tegku.

Al-Khawaldeh, O. A., Al-Hassan, M. A., \& Froelicher, E. S. (2012). Self-efficacy, selfmanagement, and glycemic control in adults with type 2 diabetes mellitus. J Diabetes Complications, 26(1), 10-16. doi:10.1016/j. jdiacomp.2011.11.002.

Amelia, R., Ariga, R.A., Rusdiana, Sari, M.I., \& Savira, M. (2018). Self-efficacy in type 2 diabetes mellitus patients and the relationship with the quality of life in Medan city. Journal of Physics: Conference Series, 1116, 052003. doi:10.1088/1742-6596/1116/5/052003.

Bahk, Y.C., \& Choi, K.H. (2018). The relationship between autobiographical memory, cognition, and emotion in older adults: a review. Neuropsychol Dev Cogn B Aging Neuropsychol Cogn, 25(6), 874-892. doi:10.1080/13825585.2017.1377681.

Bandura, A. (n.d.). Self-Efficacy (In V. S. R). New York: Academic Press.

Bowen, P.G., Clay, O.J., Lee, L.T., Vice, J., Ovalle, F., \& Crowe, M. (2015). Associations of social support and self-efficacy with quality of life in older adults with diabetes. J Gerontol Nurs, 41(12), 21-29; quiz 30-21. doi:10.3928/00989134-20151008-44.

Gedengurah, I. (2011). Efikasi diri pasien diabetes melitus tipe 2. (Self-Efficacy of Type 2 Diabetes Mellitus Patients). Jurusan
Keperawatan Politeknik Kesehatan Denpasar, 21.

Goh, S.G.K., Rusli, B.N., \& Khalid, B.A.K. (2015). Development and validation of the Asian Diabetes Quality of Life (AsianDQOL) Questionnaire. Diabetes Research and Clinical Practice, 108(3), 489-498. https:// doi.org/10.1016/j.diabres.2015.02.009.

Gomez-Pimienta, E., Gonzalez-Castro, T.B., Fresan, A., Juarez-Rojop, I.E., MartinezLopez, M.C., Barjau-Madrigal, H.A., . . ., Genis-Mendoza, A.D. (2019). Decreased quality of life in individuals with type 2 diabetes mellitus is associated with emotional distress. Int J Environ Res Public Health, 16(15). doi:10.3390/ijerph16152652.

Hazari, M.A.H., Ram Reddy, B., Uzma, N., \& Santhosh Kumar, B. (2015). Cognitive impairment in type 2 diabetes mellitus. International Journal of Diabetes Mellitus, 3(1), 19-24. doi:https://doi.org/10.1016/j. ijdm.2011.01.001.

International Diabetes Federation. (2017). IDF Diabetes Atlas. Retrieved from www. diabetesatlas.org.

Kim, B., Song, Y., \& Kim, J.S. (2019). Psychological insulin resistance and low self-efficacy as barriers to diabetes self-care management in patients with type 2 diabetes.

Kurnia, A., \& Kusumaningrum, N.S.D. (2017). Relation between self-efficacy and quality of life domain in patients with type 2 diabetes mellitus (A Case Study of Public Hospitals Type B In Semarang ). IOSR Journal of Nursing and Health Science (IOSR-JNHS), 6(6), 6. doi: 10.9790/19590606033237.

Rahman, H.F., \& Sukmarini, L. (2017). Efikasi diri, kepatuhan, dan kualitas hidup pasien diabetes melitus tipe 2 (Self efficacy, adherence, and quality of life of patients with type 2 diabetes). E-Jurnal Pustaka Kesehatan, 2, 108-113.

Riskesdas. (2018). Hasil utama riskesdas tentang prevalensi diabetes mellitus di 
Karina Megasari Winahyu: Characteristics of Patients, Self-Efficacy and Quality of Life among Patients

Indonesia 2018. (Main Results of Basic Health Research About Diabetes Mellitus Prevalence in Indonesia 2018). https://doi. org/1 Desember 2013.

Sturt, J., Hearnshaw, H., \& Wakelin, M. (2010). Validity and reliability of the DMSES UK: A measure of self-efficacy for type 2 diabetes self-management. Primary Health Care Research and Development, 11(4), 374-381. https://doi.org/10.1017/ S1463423610000101.

Wahyuni, Y., Nursiswanti, N., \& Anna, A. (2017). Kualitas hidup berdasarkan karekteristik pasien diabetes melitus tipe 2 . (Quality of Life based on Characteristics of Type 2 Diabetes Mellitus Patients). Jurnal Keperawatan Padjadjaran, 2(1), 25-34. https://doi.org/10.24198/jkp.v2n1.4.

Walker, R.J., Smalls, B.L., HernandezTejada, M.A., Campbell, J.A., \& Egede, L.E. (2014). Effect of diabetes self-efficacy on glycemic control, medication adherence, self-care behaviors, and quality of life in a predominantly low-income, minority population. Ethn Dis, 24(3), 349-355.

Wang, H.F., Chen, Y.C., Yang, F.H., \& Juan, C.W. (2017). Relationship between type 2 diabetes self-efficacy and quality of life: analysis under varying glycated hemoglobin conditions. Family Medicine \& Medical Science Research, 6(2), 11. doi:10.4172/23274972.1000218.

World Health Organization. (2019). WHOQOL: Measuring quality of life. Retrieved from https://www.who.int/ healthinfo/survey/whoqol-qualityoflife/en/.

Yamin, A., \& Sari, C.W.M. (2018). Relationship of family support towards self-management and quality of life of patients with type 2 diabetes mellitus. Jurnal Keperawatan Padjadjaran, 6(2), 175-182. https://doi.org/10.24198/jkp.v6i2.673. 